ORIGINAL ARTICLE

\title{
Infant colic and feeding difficulties
}

\author{
C Miller-Loncar, R Bigsby, P High, M Wallach, B Lester
}

Arch Dis Child 2004;89:908-912. doi: 10.1136/adc.2003.033233

See end of article for authors' affiliations

.....................

Correspondence to: Assistant Professor

Cynthia Miller-Loncar

Women \& Infants Hospital,

Infant Development Center,

111 Plain Street,

Providence, RI 02905,

USA; cynthia_loncar@

brown.edu

Accepted 5 January 2004

\begin{abstract}
Aims: To examine the relation between colic and feeding difficulties and their impact on parental functioning for a primarily clinic referred sample.

Methods: Forty three infants (and their mothers) were enrolled between 6 and 8 weeks of age. Infants were divided into two groups, colic $(n=19)$ and comparison $(n=24)$, based on a modified Wessel rule of three criteria for colic. Families were assessed at two visits; one occurred in the laboratory and one occurred in a paediatric radiology office. Outcome measures included the clinical assessment of infant oral motor skills, behavioural observation of mother-infant feeding interactions, maternal questionnaires on infant crying, sleeping and feeding behaviours, and the occurrence of gastro-oesophageal reflux (GOR) in the infants using abdominal ultrasound.

Results: Infants in the colic group displayed more difficulties with feeding; including disorganised feeding behaviours, less rhythmic nutritive and non-nutritive sucking, more discomfort following feedings, and lower responsiveness during feeding interactions. Infants in the colic group also had more evidence of GOR based on the number of reflux episodes on abdominal ultrasound as well as maternal report of reflux. Mothers in the colic group reported higher levels of parenting stress.

Conclusions: Results provide the first systematic evidence of feeding problems in a subgroup of infants with colic. Data also illustrate the impact of these difficulties on parental and infant functioning. The association between feeding difficulties and colic suggests the potential for ongoing regulatory problems in infants presenting with clinically significant colic symptoms.
\end{abstract}

A lthough excessive crying has been shown to subside for many infants from community samples within the first three months of life, these same studies identify a subgroup of infants with persistent colic symptoms. ${ }^{12}$ This suggests the need for research on clinic referred samples to assess more severe presentations of colic. Colic presents as a heterogeneous disorder with many potential causes. Feeding problems are one area that may co-occur in infants with cry problems. ${ }^{3-7}$ To date, studies have focused on factors such as formula composition ${ }^{8-10}$ or the feeding method (breast versus bottle $)^{11}$ with a reliance on retrospective parental report measures. ${ }^{12}$ Information on the association between functional measures of feeding as they relate to the infant's ability to modulate crying, such as the organisation of oral motor skills and behaviours during feeding interactions, is limited. ${ }^{13}$ Feeding and crying difficulties also may impact parental functioning through a disruption in early social exchanges, resulting in increased parental stress and depression and less optimal parent-infant interactions. ${ }^{14}{ }^{15}$ Studies examining crying and feeding difficulties note that infants with these problems are perceived as more vulnerable by their parents ${ }^{16}$ and may display later behaviour problems at preschool and early school ages. ${ }^{17} 18$

The present study examines the relation between colic and infant feeding difficulties and their impact on parental functioning for a primarily clinic referred sample. The purpose of this study was to test the hypothesis that infants with colic would have more feeding problems, including disorganised oral motor skills, gastro-oesophageal reflux (GOR), and discomfort associated with feedings, than infants without colic. We also hypothesised that colic and feeding problems, in combination, would relate to higher levels of parenting stress and lower maternal and infant responsiveness. While previous studies note that crying and feeding difficulties may co-occur, this is the first systematic comparison of infants both with and without colic on functional measures of feeding. This is not a study of the aetiology of colic or feeding problems but rather an examination of how these common paediatric concerns relate to one another in a clinic referred sample and their impact on parental and infant functioning.

\section{METHODS}

The study was approved by the institutional review boards for the Women and Infants Hospital (WIH) and Rhode Island Hospital. Forty three infants were recruited into the study between April 1998 and January 2000. Inclusion criteria consisted of infants who were 3-8 weeks of age, free of any significant perinatal insult or congenital anomalies, and taking at least two feedings per day from a bottle of either breast milk or formula. Families were recruited from community sources (childbirth education classes, paediatrician offices, and newspaper ads) and the Infant Behavior Cry and Sleep Clinic (IBCSC), a subspecialty clinic for infants with early behavioural difficulties at WIH. Families recruited from community sources were told the study was looking at general early infant behaviours of feeding, sleeping, and crying. Of the 76 families (IBCSC $=24$; community sources $=52$ ) approached about the study, $57 \%$ agreed to participate. Written informed consent was obtained from the parents at the time of the first study visit. Families brought their infants to the hospital for two visits, when the infant was between 6 and 8 weeks of age. For those infants recruited through the IBCSC, the first visit for the research protocol occurred during the intake period. The ultrasound visit occurred within one week of the intake visit.

Abbreviations: CSCL, Colic Symptom Checklist; GOR, gastrooesophageal reflux; IBCSC, Infant Behavior Cry and Sleep Clinic; I-GERQ, Infant Gastroesophageal Reflux Questionnaire; NOMAS, Neonatal Oral-Motor Assessment Scale; NPO, nothing by mouth; $\mathrm{PSI} / \mathrm{SF}$, Parenting Stress Index/Short Form; WIH, Women and Infants Hospital 
The first visit occurred at the Infant Development Center at WIH and was scheduled around the time of the infant's feeding. At this visit, colic symptoms were assessed and infants were divided into two groups, Colic and Comparison. Infants who met criteria for a modified Wessel "rule of three" for excessive crying using parental report were assigned to the colic group. ${ }^{19}$ These were infants who cried for three or more hours per day, for at least three days of the week, for at least three weeks. There were 19 infants in the colic group and 24 infants in the comparison group. Seventy nine percent of infants in the colic group came from the sample recruited from the IBCSC and $96 \%$ of infants in the comparison group came from community sources.

\section{Measures}

The Colic Symptom Checklist (CSCL) measured additional colic symptoms, including (1) excessive crying; (2) paroxysmal onset; (3) qualitative difference in cry; (4) physical discomfort signals; and (5) inconsolability. ${ }^{20}$ Criteria selection was based on literature noting use of these characteristics to describe infants with colic. ${ }^{21}$ Construct validity for the CSCL is shown in research showing differences in cry acoustics for infants with colic versus those without colic. ${ }^{22}$ Infants received one point for each of the five criteria that were met on the CSCL to enable us to score the number of additional colic symptoms that occurred with excessive crying.

A clinical assessment of infant oral motor skills also occurred at the first visit. The Neonatal Oral-Motor Assessment Scale (NOMAS) ${ }^{23}$ and the Clinical Feeding Evaluation $^{24}$ examine oral-motor performance during both nutritive and non-nutritive sucking. On the NOMAS, infants are scored for their overall classification of normal, disorganised, or dysfunctional patterns as well as the occurrence of disorganised behaviours. Disorganised feeding is characterised by arrhythmic jaw movements, difficulty coordinating sucking, swallowing, and breathing, and an inability to slow down the sucking rate for nutritive intake. The clinical feeding evaluation is scored for organised versus disorganised feeding behaviours. Research staff, masked to colic group status, were trained to reliability $(\mathrm{kappa}=0.78)$ by an occupational therapist with expertise in both measures. In addition, reliability for $9 \%$ of the data was calculated with a kappa agreement of 0.87 .

A videotaped observation of a mother-infant feeding interaction was done at the first visit. An examiner masked to group status was trained to reliability for the coding of infant feeding behaviours and maternal responsiveness using training tapes of infant feeding from a separate study that utilised the same procedure..$^{25-27}$ Intra-class correlations for the coder with the gold standard training tapes was 0.80 . Three infant ratings (appropriateness of infant state for feeding, ease of feeding, and general responsiveness to their mothers) and seven maternal ratings (quality of physical contact, determination of feeding, tone of voice, attentiveness, confidence, delight, and appropriateness of feeding behaviour) were coded. These ratings were averaged to form two separate composites for infant responsiveness and maternal responsiveness.

Mothers also received questionnaires on infant reflux, behavioural diaries, and a measure of parenting stress. The Infant Gastroesophageal Reflux Questionnaire (I-GERQ) is a parent interview developed by paediatric gastroenterologists to identify infants with clinically significant GOR. ${ }^{28}$ Items refer to how often and how much the infant spits up, if there is discomfort associated with it, hours of crying/fussing, and feeding refusals. The I-GERQ assigns three points for crying in excess of three hours per day. The I-GERQ uses a cut-off score of $>7$ to categorise an infant as GOR positive.
Mothers were asked to keep infant behaviour diaries for three days. Behaviours were recorded across a 24 hour period that was broken into 15 minute intervals. Mothers coded the infant's predominant behaviour (that is, awake, crying/ fussing, feeding, sleeping) for each 15 minute period over the course of the day. Averages were calculated for time spent awake, crying/fussing, feeding, episodes of discomfort following feeding, and sleeping. Five families did not complete diaries $($ colic $=1$; comparison $=4$ ) due to reported parental time constraints with recording their infant's behaviour. General parenting stress was measured using the Parenting Stress Index/Short Form (PSI/SF) with higher scores indicating greater parental stress. ${ }^{29}$ The above measures were collected at the time of the ultrasound visit.

The second visit occurred within two weeks of the laboratory visit at the Pediatric Radiology Department of Hasbro Children's Hospital in Providence to assess the occurrence of reflux in the infants using abdominal ultrasound. An abdominal ultrasound was conducted by a radiologist masked to group status. Abdominal ultrasound was used as an effective non-invasive diagnostic examination to confirm GOR. Previous research shows $84-87 \%$ agreement between $\mathrm{B}$-mode ultrasound and $\mathrm{pH}$ probe for identifying the presence of GOR. ${ }^{30}{ }^{31}$ Infants were required to take nothing by mouth (NPO) three hours prior to the examination. The ultrasound examination consisted of a study of upper gastrointestinal anatomy to the duodenojejunal flexure, and examined the solid abdominal organs. Infants drank two ounces of sugar water and then were monitored for episodes of GOR for a prescribed period of time (five minutes). The number of reflux episodes that occurred across the five minute period was recorded. Four infants ( colic $=2$; comparison $=2$ ) did not receive an abdominal ultrasound due to parents refusing consent.

Data were analysed using the statistical program SPSS 8.75 for Windows (SPSS Inc., Chicago, IL). $\chi^{2}$ statistics and $t$ tests were used to compare the colic and comparison groups on medical and demographic characteristics as well as to compare group differences on the dependent variables of colic symptoms, feeding difficulties, GOR, infant behaviours, maternal and infant responsiveness, and parenting stress. Stepwise regression analyses were conducted to examine the relation between colic and feeding difficulties with measures of infant and parent functioning.

\section{RESULTS}

Table 1 presents the birth and maternal characteristics for colic and comparison groups. The sample consisted of healthy, full term infants. Groups were not significantly different on any maternal or infant demographic characteristics. Use of hypoallergenic formulas was reported for four infants in the colic group but neither group reported use of hypoallergenic maternal diets. Income levels based on the Hollingshead four factor index fell in the middle to upper middle class range. ${ }^{32}$ Mothers reported moderate satisfaction with the help received from social support of family and friends.

Table 2 presents results for the initial question of whether infants with colic displayed more feeding difficulties. A greater proportion of infants in the colic group displayed disorganised feeding and an overall diagnosis of a disorganised feeding pattern on the NOMAS compared to infants in the comparison group. Fewer infants in the colic group exhibited rhythmic nutritive and non-nutritive sucking. Infants in the colic group also had more reflux episodes based on abdominal ultrasound, had higher mean I-GERQ scores, and were more likely to score above the clinical cut-off of 7 for reflux on the I-GERQ. Because infants referred to the clinic were typically crying for more than three hours per day, 
Table 1 Maternal and infant demographic information

\begin{tabular}{|c|c|c|c|}
\hline & \multicolumn{2}{|l|}{ Group* } & \multirow[b]{2}{*}{$p$ value } \\
\hline & $\begin{array}{l}\text { Colic } \\
(n=19)\end{array}$ & $\begin{array}{l}\text { Comparison } \\
(n=24)\end{array}$ & \\
\hline \multicolumn{4}{|l|}{ Mean (SD) } \\
\hline Mother's age (y) & $30.1(5.4)$ & $29.3(4.8)$ & 0.47 \\
\hline Mother's education (y) & $14.7(2.1)$ & $14.8(2.1)$ & 0.85 \\
\hline Infant age at entry (wk) & $5.8(1.7)$ & $5.5(1.3)$ & 0.53 \\
\hline Birth weight $(\mathrm{kg})$ & $3.3(.41)$ & $3.5(.47)$ & 0.36 \\
\hline Socioeconomic status $†$ & $45.6(8.9)$ & $45.5(14.3)$ & 0.96 \\
\hline Social support & $26.5(9.9)$ & $29.9(9.3)$ & 0.25 \\
\hline Maternal depression $\ddagger$ & $7.7(4.8)$ & $6.8(4.1)$ & 0.54 \\
\hline \multicolumn{4}{|l|}{ n (\%) } \\
\hline \multicolumn{4}{|l|}{ Infant nutrition } \\
\hline Formula & $8(42)$ & $8(33)$ & \\
\hline Breast milk & $2(11)$ & 3 (13) & \\
\hline Breast milk and formula & $9(47)$ & $13(54)$ & 0.84 \\
\hline \multicolumn{4}{|l|}{ Marital status } \\
\hline Married & $18(95)$ & $23(96)$ & 0.71 \\
\hline Female/male & $9(47) / 10(53)$ & $9(38) / 15(62)$ & 0.52 \\
\hline \multicolumn{4}{|c|}{ 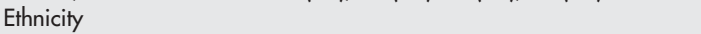 } \\
\hline Caucasian & $17(90)$ & $22(92)$ & 0.49 \\
\hline African-American & $1(5)$ & $0(0)$ & \\
\hline Hispanic & $1(5)$ & $2(8)$ & \\
\hline
\end{tabular}

*There were no significant differences between the two groups for these variables.

†Socioeconomic status was measured by the Hollingshead four factor index.

$\ddagger$ Maternal depression was measured by the Beck Depression Inventory

a higher GOR cut-off category of 10 was also examined. The results using the higher cut-off category were statistically comparable for group differences $(p<0.0001)$.

Data from the behaviour diaries indicated that infants in the colic group cried almost twice as much as infants in the comparison group. Infants in the colic group also spent less time in an awake, non-crying state and showed more episodes of discomfort following a feeding than infants in the comparison group. The mean number of additional colic symptoms on the CSCL also was higher in the colic group than in the comparison group (see table 2 ).

Infants in the colic group also were less responsive towards their mothers during feeding interactions than infants in the comparison group. With regard to parent functioning, mothers in the colic group reported higher levels of stress as compared to mothers in the comparison group.

Table 3 presents stepwise regression analyses that examine the relation between colic, feeding difficulties, and the outcomes of infant responsiveness and parenting stress. To guard against over-specification in the regression models, Pearson correlations were used to inform the analysis (see table 4). Colic was entered first in the models followed by a specific feeding difficulty. Predictors of infant responsiveness included both colic and reflux episodes. However, colic was no longer a significant predictor of infant responsiveness when the impact of reflux was taken into account. The model predicting parenting stress contained colic and feeding discomfort. Again, colic was no longer a significant predictor of parenting stress when feeding discomfort was included.

\section{DISCUSSION}

The current findings provide clear evidence of feeding related problems in four distinct areas for a clinic referred sample of infants with colic. These infants showed: (1) more evidence of reflux, both on ultrasound and on the I-GERQ questionnaire; (2) more sucking and feeding problems on the NOMAS and Clinical Feeding Evaluation as evidenced by arrhythmic jaw movements and difficulty coordinating sucking, swallowing, and breathing; (3) less responsiveness during a videotaped feeding interaction; and (4) more episodes of feeding discomfort as recorded by mothers on behaviour diaries. This study provides the first systematic evidence of functional feeding problems in infants with colic.

\begin{tabular}{|c|c|c|c|c|}
\hline & \multicolumn{2}{|l|}{ Group } & \multirow[b]{2}{*}{$\mathbf{F}$} & \multirow[b]{2}{*}{ p value } \\
\hline & Colic & Comparison & & \\
\hline Colic Symptom Checklist & $4.5(4.1-4.8)$ & $0.79(0.22-1.4)$ & 116.27 & 0.0001 \\
\hline \multicolumn{3}{|l|}{ Clinical feeding evaluations, n (\%) } & \multicolumn{2}{|l|}{$\chi^{2}$} \\
\hline Presence of disorganised feeding & $8(42)$ & $2(8)$ & 6.78 & 0.009 \\
\hline Overall disorganised feeding pattern & $3(15)$ & $0(0)$ & 4.07 & 0.04 \\
\hline Rhythmic nutritive sucking & $10(53)$ & $23(96)$ & 11.09 & 0.001 \\
\hline Rhythmic non-nutritive sucking & $13(77)$ & $24(100)$ & 6.25 & 0.01 \\
\hline \multicolumn{3}{|l|}{ Reflux problems } & \multicolumn{2}{|l|}{$\mathbf{F}$} \\
\hline Reflux episodes by ultrasound & $3.1(2.3-3.9)$ & $2.1(1.5-2.7)$ & 4.15 & 0.049 \\
\hline \multicolumn{3}{|l|}{ I-GERQ clinic cut-offs, n (\%) } & 28.36 & 0.0001 \\
\hline$>7$ & $17(89)$ & $5(21)$ & \multicolumn{2}{|l|}{20.91} \\
\hline$\leqslant 7$ & $2(11)$ & $19(79)$ & & 0.0001 \\
\hline \multicolumn{3}{|l|}{ Behavioural diaries $\dagger$} & \multicolumn{2}{|l|}{$\mathbf{F}$} \\
\hline Hours crying & $4.8(3.3-6.3)$ & $2.5(1.9-3.1)$ & 9.99 & 0.003 \\
\hline Hours sleeping & $12.4(11.1-13.7)$ & $12.9(12.1-13.7)$ & 0.45 & 0.51 \\
\hline Hours awake (but not crying or feeding) & $3.3(2.3-4.3)$ & $5.3(4.8-5.9)$ & 14.01 & 0.001 \\
\hline Hours feeding & $3.5(2.9-4.3)$ & $3.3(2.7-3.7)$ & 1.25 & 0.27 \\
\hline \multicolumn{5}{|l|}{ Mother-infant feeding interactions $\neq$} \\
\hline Maternal responsiveness & $41.1(37.7-44.6)$ & $42.7(38.9-46.5)$ & 0.37 & 0.54 \\
\hline \multicolumn{5}{|l|}{ Parental functioning§ } \\
\hline Parenting stress index & $76.7(66.4-87.1)$ & $61.5(53.2-69.9)$ & 5.87 & 0.02 \\
\hline $\begin{array}{l}\text { *Values are mean }(95 \% \mathrm{Cl}) \text { unless otherw } \\
\text { †Diaries are based on average of behavi } \\
\text { categories. } \\
\text { †Feeding interactions are based on video } \\
\text { \$Higher scores indicate greater parenting }\end{array}$ & $\begin{array}{l}\text { stated. } \\
\text { rs across three } 24 \\
\text { ped observations. } \\
\text { tress. }\end{array}$ & ays; hour counts & nutually & clusive \\
\hline
\end{tabular}


Table 3 Stepwise regression analyses of colic and feeding difficulties

\begin{tabular}{|c|c|c|c|c|}
\hline Outcome variable & Predictor variables & $\begin{array}{l}\text { Overall significance } \\
\text { of model }\end{array}$ & $R^{2}$ value & $\begin{array}{l}\text { Beta } \\
\text { coefficients }\end{array}$ \\
\hline \multirow[t]{2}{*}{ Infant responsiveness } & $\begin{array}{l}\text { Step } 1 \\
\text { Colic }\end{array}$ & $F=6.63, p<0.01$ & 0.14 & $-038^{* *}$ \\
\hline & $\begin{array}{l}\text { Step } 2 \\
\quad \text { Colic } \\
\text { Reflux episodes }\end{array}$ & $F=4.06, p=0.03$ & 0.19 & $\begin{array}{l}-0.20 \\
-0.33^{*}\end{array}$ \\
\hline \multirow[t]{2}{*}{ Parenting stress } & $\begin{array}{l}\text { Step } 1 \\
\quad \text { Colic }\end{array}$ & $F=5.87, p=0.02$ & 0.13 & $0.37^{*}$ \\
\hline & $\begin{array}{l}\text { Step } 2 \\
\quad \text { Colic } \\
\text { Feeding discomfort episodes }\end{array}$ & $F=5.68, p<0.01$ & 0.25 & $\begin{array}{l}0.04 \\
0.48^{* *}\end{array}$ \\
\hline
\end{tabular}

Table 4 Correlations for measures of colic, feeding difficulty, and infant and parent functioning

\begin{tabular}{lccccccc}
\hline & Colic & Reflux & I-GERQ & Feeding discomfort & Disorganised & Infant responsiveness & Parenting stress \\
\hline Colic & - & & & & & & \\
Reflux & $0.32^{*}$ & - & & & & & \\
I-GERQ & $0.64^{* * *}$ & 0.30 & - & & & & \\
Feeding discomfort & $0.44^{* *}$ & 0.31 & $0.34^{*}$ & - & - & & \\
Disorganised feeding & $0.38^{* *}$ & 0.23 & $0.37^{*}$ & -0.03 & -0.09 & - & - \\
Infant responsiveness & $-0.38^{* *}$ & $-0.39^{*}$ & -0.10 & -0.16 & 0.01 & \\
Parenting stress & $0.37^{*}$ & 0.04 & 0.25 & $0.50^{* *}$ & 0.26 & & \\
\hline${ }^{*} \mathrm{p}<0.05,{ }^{* *} \mathrm{p}<0.01,{ }^{* * *} \mathrm{p}<0.001$ & & & & & & \\
\hline
\end{tabular}

Previous work has examined crying as a symptom of feeding problems. For example, crying during or after a feed is associated with feeding problems such as GOR, feeding refusals, and nipple confusion. In a pilot study, we found evidence of disorganised sucking on the NOMAS in infants with colic. ${ }^{13}$ Factors such as underfeeding, overfeeding, swallowing excessive amounts of air, or not being adequately burped also have been cited as contributing to colic. ${ }^{33}$ Early paediatric textbooks attribute colic to immaturity of the gastrointestinal tract, ${ }^{34}$ including the idea that the hypertonic gut undergoes a spasm that produces the symptoms of colic. ${ }^{35}$ Thus, the colic folklore includes the idea that colicky infants have more feeding problems. There is also evidence suggesting that $5-10 \%$ of colic cases are due to organic disturbances, such as gastrointestinal disorders. ${ }^{36}$ A limitation of the present study was the measurement of GOR via abdominal ultrasound. This study utilised abdominal ultrasound as a non-invasive diagnostic examination to confirm GOR. Previous studies note $84-87 \%$ agreement between ultrasound methods and standard $\mathrm{pH}$ probe procedures. ${ }^{30}{ }^{31}$ However, the clinical significance of the ultrasound results should be interpreted with caution as it is not standard practice for diagnosing GOR.

We cannot, however, determine if there is a causal relation between colic and feeding problems from this study. It is possible that feeding problems contribute to colic symptoms, or that colic contributes to feeding problems, or that they are co-occurring conditions with similar aetiologies. One possibility is that disorganised feeding patterns in infants with colic indicate an underlying disorder in behavioural regulation. Infants with colic are noted to show higher pitched, more turbulent cries following a feeding as indicated by cry acoustics. ${ }^{37}$ Acoustic differences may reflect a difficulty for infants with colic to regulate their arousal. Other work has shown that regulatory difficulties with crying during infancy are related to later problems in sensory integration, attention, and behavioural development. ${ }^{198}$ The DeSantis study examined behaviours for a group of children 3-8 years of age who were referred for clinical treatment of colic during infancy. At later ages, these children were reported by parents and teachers to exhibit difficulties with sensory processing, emotional reactivity, and inattention. This suggests that some underlying dysregulation may be present in children presenting with clinical levels of colic.

A common paediatric belief is that if infants are growing and developing normally, it is not necessary to intervene in infant cry problems, as these difficulties resolve with time. Results show that infants brought into a clinic for cry problems had more feeding difficulties, were less responsive, and had mothers who reported more stress, compared to infants from community sources. Past research indicates that parents who are stressed by their parenting role are less effective in their interactions with their child. ${ }^{39}$ Parents who come into a clinic for their infant's behaviour problems may present on the more extreme end of the colic continuum, which is why they were seen in our clinic. This hypothesis is supported by the fact that the mean score on the CSCL in the colic group was 4.5 , with 5 as the maximum score possible. Because this is a clinic referred sample, the present findings have limited generalisability to larger community based samples of infants with colic. However, it is important to consider clinically referred groups where parents identify their infant's crying behaviour as problematic, as it appears to impact both infant and parent functioning, a finding supported by previous research. ${ }^{14}$ While population based research indicates that colic does not have a lasting impact on parental functioning, our findings highlight the need to provide information and support for parents whose infants present with clinically diagnosed levels of colic and associated feeding problems.

In general, comparison of findings across colic samples is difficult due to the use of varying definitions. Reijneveld et al note that the lack of clear definitions for colic has a significant impact on prevalence rates. ${ }^{40}$ The majority of studies use the Wessel "rule of 3 " to define colic and therefore provide the minimal information on the symptomatology of the infants. There might be greater generalisability across studies if we also knew whether study samples included infants with additional, more extreme symptoms, such as those measured by the CSCL. Our findings that the 
CSCL was related to GOR and disorganised feeding behaviour support the predictive validity of this scale. Community based studies note that colic persists for a subgroup of infants. ${ }^{1}$ The CSCL may be useful as a measure of the severity of colic and for identifying those infants whose colic symptoms persist over time.

Problems with crying and feeding are two of the most common paediatric concerns of parents in early infancy. ${ }^{41} \mathrm{We}$ have shown that these problems are related in infants presenting with clinically significant levels of colic. While the present results may not readily generalise to community samples of infants with colic, it provides useful information to a specific clinic referred subsample of infants. The sample is nonetheless limited by its size and a larger study needs to replicate the current findings in order to determine whether feeding presents a reasonable area on which to focus interventions.

\section{ACKNOWLEDGEMENTS}

The authors would like to thank Katherine Halloran for her diligence in recruitment and data collection.

\section{Authors' affiliations}

C Miller-Loncar, R Bigsby, P High, B Lester, Brown Medical School, Department of Pediatrics, Infant Development Center, Women and Infants Hospital of Rhode Island \& E. P. Bradley Hospital, Providence, RI, USA

M Wallach, Hasbro Children's Hospital, Providence, RI, USA

This research was supported by a grant from the Gerber Foundation

\section{REFERENCES}

1 Clifford TJ, Campbell MK, Speechley KN, et al. Sequelae of infant colic: evidence of transient infant distress and absence of lasting effects on maternal mental health. Arch Pediatr Adolesc Med 2002;156:1183-8.

2 Illingworth RS. Three month's colic. Arch Dis Child 1954;29:165-74.

3 Asnes RS, Mones RL. Infantile colic: a review. J Dev Behav Pediatr 1982;4:57-62.

4 Berkowitz D, Naveh Y, Berant M. "Infantile colic" as the sole manifestation of gastroesophageal reflux. J Pediatr Gastroenterol Nutr 1997;24:231-3.

5 Dellert SF, Hyams JS, Treem WR, et al. Feeding resistance and gastroesophageal reflux in infancy. J Pediatr Gastroenterol Nutr 1993; 17:66-71.

6 Feranchak AP, Orenstein SR, Cohn JF. Behaviors associated with the onset of gastroesophageal reflux episodes in infants: prospective study using split screen video and pH probe. Clin Pediatr 1994;33:654-62.

7 Nelson SP, Chen EH, Syniar GM, et al. Prevalence of symptoms of gastroesophageal reflux during infancy: a pediatric office based survey. Arch Pediatr Adolesc Med 1997;151:569-72.

8 Forsyth BWC. Colic and the effect of changing formulas: a double-blind, multiple crossover study. J Pediatr 1989;115:521-52.

9 Lothe L, Lindberg T. Cow's milk whey protein elicits symptoms of infantile colic in colicky formula-fed infants: a double blind crossover study. J Pediatr 1989;83:262-6

10 Oberlander TF, Barr RG, Young SN, et al. Short-term effects of feed composition on sleeping and crying in newborns. Pediatrics 1992;90:733-40

11 Lucas A, St James-Roberts I. Crying, fussing and colic behavior in breast- and bottle-fed infants. Early Hum Dev 1998;53:9-18.

12 Wolke D, Meyer R, Ohrt B, et al. Co-morbidity of crying and feeding problems with sleeping problems in infancy: concurrent and predictive associations. Early Dev Parent 1995;4:191-207.
13 Ferguson A, Bier JB, Cucca J, et al. The quality of sucking in infants with colic. Inf Ment Health 1996;17:161-9.

14 Papousek $M$, van Hofacker N. Persistent crying in early infancy: a non-trivial condition of risk for the developing mother-infant relationship. Child Care Health Dev 1998;24:395-424.

15 Lester BM, Boukydis CFZ, Garcia-Coll CT, et al. Developmental outcome as a function of the goodness of fit between the infant's cry characteristics and the mother's perception of her infant's cry. Pediatrics 1995:95:516-21.

16 Forsyth BWC, Canny PF. Perceptions of vulnerability 3 and a half years after problems of feeding and crying behavior in early infancy. Pediatrics $1991 ; 88: 757-63$

17 Rautava $\mathrm{P}$, Lehtonen $\mathrm{L}$, Helenius $\mathrm{H}$, et al. Infantile colic: child and family three years later. Pediatrics 1995;96:43-7.

18 DeSantis A, Coster W, Bigsby R, et al. Colic and fussing in infancy and sensory processing at 3-8 years of age. Inf Ment Health. In press.

19 Wessel MA, Cogg JC, Jackson EB, et al. Paroxysmal fussing in infancy, sometimes called "colic". Pediatrics 1954;14:421-34.

20 Lester BM, Boukydis CFZ, Garcia-Coll CT, et al. Colic for developmentalists. Inf Ment Health 1990;11:321-33.

21 Barr R. The normal crying curve: what do we really know? Dev Med Child Neurol 1990;32:356

22 Lester BM, Boukydis CFZ, Garcia-Coll CT, et al. Infantile colic: acoustic cry characteristics, maternal perception of cry, and temperament. Inf Behav Dev 1992;15:15.

23 Palmer MM, Crawley K, Blanco I. The Neonatal Oral-Motor Assessment scale: a reliability study. J Perinatol 1993;13:28-35.

24 Wolf LS, Glass RP. Feeding and swallowing disorders in infancy: assessment and management. San Antonio, TX: The Psychological Corporation, 1992.

25 Garcia-Coll CT, Halpern L, Seifer R, et al. Behavioral intervention ad postnatal growth in full-term intrauterine growth retarded (IUGR) infants. Early Hum Dev 1996;46:105-16.

26 Meyer EC, Garcia Coll CT, Lester BM, et al. Family-based intervention improves maternal psychological well-being and feeding interaction of preterm infants. Pediatrics 1994;93:241-6.

27 LaGasse L, Messinger D, Lester B, et al. Prenatal drug exposure and maternal and infant feeding behaviour. Arch Dis Child, In press.

28 Orenstein SR, Shalaby TM, Cohn JF. Reflux symptoms in 100 normal infants: diagnostic validity of the Infant Gastroesophageal Reflux Questionnaire. Clin Pediatr 1996;35:607-14.

29 Abidin A. Parenting Stress Index/Short Form. Charlottesville, VA: Pediatric Psychology Press, 1990.

30 Hirsch W, Kedar R, Preiss U. Color Doppler in the diagnosis of gastroesophageal reflux in children: comparison with $\mathrm{pH}$ measurements and B-mode ultrasound. Pediatr Radiol 1996;26:232-5.

31 Westra SJ, Wolf BH, Staalman CR. Ultrasound diagnosis of gastroesophageal reflux and hiatal hernia in infants and young children. J Clin Ultrasound 1990; 18:477-85

32 Hollingshead AB. Four factor index of social status, Available through the Department of Sociology, Yale University, New Haven CT, 1975.

33 Carey WB. "Colic" - primary excessive crying as an infant-environment interaction. Pediatr Clin North Am 1984;31:993-1005.

34 Gordon DA. The hypertonic child: theories and description. Arch Pediatr 1948;65:70-83.

35 Adams LM, Davidson M. Present concepts of infant colic. Pediatr Ann 1987; 16:817-20

36 Barr RG, Rappaport L. Infant colic and childhood recurrent abdominal pain syndromes: is there a relationship? J Dev Behav Pediatr 1999:20:315-17.

37 Zeskind PS, Barr RG. Acoustic characteristics of naturally occurring cries of infants with "colic". Child Dev 1997;68:394-403.

38 DeGangi GA, Porges SW, et al. Four-year follow-up of a sample of regulatory disordered infants. Inf Ment Health J 1993;14:330-43.

39 Crnic KA, Greenberg MT, Ragozin AS, et al. Effects of stress and social support on mothers of premature and full term infants. Child Dev 1983:54:209-17.

40 Reijneveld SA, Brugman E, Hirasing RA. Excessive infant crying: the impact of varying definitions. Pediatrics 2001;108:893-7.

41 Forsyth BWC, McCarthy PL, Leventhal JM. Problems of early infancy, formula changes, and mothers' beliefs about their infants. J Pediatr $1985 ; 106: 1012-17$. 